\title{
\#EleNão (Él no): tecnofeminismo interseccional en Brasil frente al ascenso del neoconservadurismo evangélico y el posfascismo*
}

\author{
\#EleNão (Not him): \\ Intersectional techno-feminism in Brazil against the ascent \\ of evangelical neoconservatism and post-fascism
}

KARINA BÁRCENAS BARAJAS**

\begin{abstract}
This paper aims to analyze the way women who embody diverse inequalities - gender, race, ethnicity, sexual orientation, gender identity religion-produced an intersectional techno-feminism to position themselves against the post-fascism promoted by Jair Bolsonaro. During his 2018 presidential campaign, intersectional technofeminism made evident Jair Bolsonaro's post-fascist alliances with a predominantly pentecostal and neopentecostal evangelical sector, as well as its affinities with a neoliberal model. For this demonstration, it was used a methodological strategy based on digital ethnography, through which the technopolitical tactics - that is, between the internet and the street- that the Facebook group Women United Against Bolsonaro articulated.
\end{abstract}

Key words: technopolitics, feminisms, inequalities, collective action, digital ethnography

\begin{abstract}
Resumen
Este artículo se propone analizar cómo, mujeres que encarnan diversas desigualdades -por género, raza, etnia, orientación sexual, identidad de género y religión-, produjeron un tecnofeminismo interseccional, para posicionarse contra el posfascismo que promovió Jair Bolsonaro durante su campaña presidencial de 2018 , la cual evidenció sus alianzas con un sector evangélico, predominantemente pentecostal y neopentecostal, así como sus afinidades con un modelo neoliberal. Para ello, se recurrió a una estrategia metodológica fundamentada en la etnografía digital, por medio de la cual se estudiaron las tácticas tecnopolíticas -entre internet y la calle- que el grupo en Facebook Mujeres Unidas contra Bolsonaro articuló.
\end{abstract}

Palabras clave: tecnopolítica, feminismos, desigualdades, acción colectiva, etnografía digital

\footnotetext{
* Artículo recibido el 26/07/19 y aceptado el 20/12/19.

** Universidad Nacional Autónoma de México (unAm)-Instituto de Investigaciones Sociales. Circuito Mario de la Cueva s / n, Ciudad de la Investigación en Humanidades, Ciudad Universitaria, Coyoacán, 04510, Ciudad de México, cDmx <kb.barcenas@ sociales.unam.mx> ORCID: https: / / orcid.org/0000-0002-4741-6199.

Agradezco el financiamiento del Programa de Apoyo a Proyectos de Investigación e Innovación Tecnológica (PAPIT) de la UNAM para la realización de este artículo, como parte del proyecto "Entre el sexularismo y el neoconservadurismo. Las Iglesias evangélicas y cristianas en México y Brasil en las disputas por la regulación de la moral sexual contemporánea", clave IA300719.
} 


\section{Introducción: resistencia y esperanza tecnofeminista en Brasil}

\author{
Una mañana, yo desperté \\ y resonaba él no, él no, no, no, no. \\ Una mañana, yo desperté \\ y luché contra un opresor. \\ Somos mujeres, la resistencia \\ de un Brasil sin fascismo y sin horror. \\ Vamos a luchar para derrotar \\ el odio y predicar el amor.
}

Simone Soares y Flávia Simão ${ }^{1}$

$\mathrm{E}$ sta versión de la canción Bella Ciao se convirtió en un himno de la resistencia feminista ante el posfascismo que anunciaba la candidatura de Jair Bolsonaro a la presidencia de Brasil. El activismo feminista desde internet hacia las calles tiene antecedentes en ese país. Uno de ellos es Blogueras Feministas, que surgió de una lista de correos electrónicos con el objetivo de debatir cuestiones políticas relacionadas con las mujeres en la primera vuelta de las elecciones de 2010; posteriormente, esta iniciativa avanzó a la creación de un blog en WordPress gestionado de manera colaborativa y con canales de difusión a través del correo electrónico y las redes sociodigitales (Branco de Castro Ferreira, 2015).

Asimismo, desde 2011 , diversas manifestaciones anuales en el espacio público contra la violencia de género, como la Marcha de las Putas, son convocadas y coordinadas desde internet -mediante blogs y redes sociodigitales como Facebook y Twitter-(Branco de Castro Ferreira, 2015). Años más tarde, de 2015 a 2016, también fueron relevantes en el activismo feminista de internet a la calle las protestas contra los estereotipos de mujeres en los medios y en la vida política, ${ }^{2}$ así como contra la violencia sexual que se ejerce en su contra ${ }^{3}$ (Matos, 2017: 423; Silva Reis, 2017: 6).

Sin embargo, el 31 de agosto de 2018 surgió en Brasil un movimiento de mujeres paradigmático que, por medio de un grupo en Facebook, se posicionó de manera abierta contra la candidatura presidencial de Jair Bolsonaro, del Partido Social Liberal (PSL), con la consigna \#EleNão (Él no). Desde febrero de 2017
Bolsonaro dejó en claro sus alianzas políticas con algunos sectores evangélicos y mostró un discurso que resultó atractivo para gran parte de sus votantes: "el Estado es cristiano. Vamos a hacer un Brasil para las mayorías. Las minorías se adecuan o simplemente desaparecen" (Bolsonaro, cit. en Aguirre, 2018). Esta perspectiva marcó su lema de campaña con el que enfatizó: "Brasil por encima de todo, Dios por encima de todos".

Si bien las movilizaciones en internet y en la vía pública orquestadas por el grupo Mujeres Unidas contra Bolsonaro estaban claramente orientadas contra el fascismo y en favor de la democracia, conviene situarnos en lo que Enzo Traverso denomina posfacismo, ${ }^{4}$ ya que, aun cuando el discurso neoconservador de Bolsonaro enfatiza una ideología nacionalista, antidemocrática y en pro de la militarización, se separa de los fascismos clásicos del siglo xx por sus entramados con el neoliberalismo y su carencia de un programa político.

Para Traverso (2018: 19, 33, 44), el posfacismo tiene un régimen de historicidad diferente -situado al comienzo del siglo xxI- y se separa del carácter estatista y antiimperialista de los fascismos clásicos, así como de su ambición por "fundar su política sobre un nuevo proyecto y una nueva visión del mundo". No obstante, el discurso de Bolsonaro evidenció cómo el posfacismo que encarna conserva de los fascismos clásicos "una matriz antifeminista, negrófoba, antisemita y homofóbica" (Traverso, 2018: 45).

La postura neoconservadora y posfascista que Bolsonaro promovió desde su campaña mostró los riesgos que en términos de derechos y libertades enfrentarían diversas poblaciones atravesadas por una o varias desigualdades que se tejen desde el género, la orientación sexual, la identidad de género, la raza, la pertenencia étnica y la religión. En tal contexto, esta iniciativa, que nació en las redes sociodigitales gracias al grupo Mujeres Unidas contra Bolsonaro, representa una innovadora apuesta dentro de lo que se puede denominar un tecnofeminismo interseccional.

Con él se visibiliza, se problematiza y se pretende combatir la manera en que dos o más de las desigualdades enunciadas se encarnan en el cuerpo y en la identidad de las mujeres, para producir "una constelación de relaciones de poder que se cruzan y

1 Versión de Bella Ciao compuesta por Simone Soares y Flávia Simão. La letra original fue un himno de resistencia ante el fascismo de Benito Mussolini.

2 A través de hashtags como \#BelaRecatadaEdoLar, \#MamiloLivre, \#VaiTerShortinhoSim, \#MarchadasMulheresNegras, \#MarchadasMargaridas, \#SomostodosMaju, \#SomostodosTaisAraujo, \#SomostodosCrisViana, \#MulheresContraCunha.

3 Mediante hashtags como \#primeiroassedio, \#VamosJuntas?, \#MexeucomUmaMexeucomTodas, \#ContraaCulturado Estupro.

4 Traverso (2018: 18) también hace una distinción entre posfascismo y neofascismo, argumentando que este último se refiere a los vestigios, a un fenómeno residual o a los intentos por prolongar y generar una vez más el viejo fascismo. 
producen realidades materiales y experiencias sociales disímiles para los individuos y grupos ubicados dentro de ellas" (Hill Collins y Chepp, 2013: 60).

La creadora de Mujeres Unidas contra Bolsonaro fue Ludmilla Teixeira (36 años) quien vive en Salvador de Bahía. En sus redes sociales se describe como una mujer negra, feminista, nordestina, defensora de los animales y las minorías, agnóstica, activista y anarco. El éxito del grupo fue inmediato entre quienes veían amenazada su existencia, sus derechos y sus libertades por la candidatura de Bolsonaro.

A mediados de septiembre de 2018, el grupo ya contaba con más de un millón de integrantes y aumentaba diez mil miembros por minuto (Arias, 2018), mientras que para la segunda vuelta de las elecciones -en octubre de 2018- estuvo conformado por más de cuatro millones de miembros, y fue comandado por 80 administradoras y moderadoras, quienes tenían un perfil semejante al de su fundadora, es decir, mujeres con antecedentes de participación en movimientos sociales, con formación universitaria y profesionistas.

Para situar la resistencia que representó Mujeres Unidas contra Bolsonaro es importante considerar que, de acuerdo con el GlobalWebIndex, Brasil es el segundo país que pasa más tiempo en las redes sociodigitales y el tercero con el mayor tiempo en internet (Sánchez, 2018). Además de que son las mujeres quienes ingresan más a internet (53\% en relación con $47 \%$ de los hombres) (Silva Reis, 2017: 2).

En este contexto fue que cuatro millones de mujeres que encarnan diversas desigualdades -que pueden ser leídas en clave interseccional-se conectaron entre sí, a través de un grupo en Facebook, creando lo que Manuel Castells (2012) denomina redes de esperan$z a$. Desde su perspectiva, la unión ayuda a superar el miedo, "esa emoción paralizante de la que se vale el poder para prosperar y reproducirse mediante la intimidación o la disuasión y, si es necesario, mediante la pura violencia, manifiesta o impuesta desde las instituciones" (Castells, 2012: 20).

Para Castells, "el big bang de un movimiento social empieza con la transformación de la emoción en acción”, es decir, se requiere superar el efecto paralizante del miedo y la ansiedad -como una respuesta ante una amenaza externa-para dar paso al entusiasmo, donde se construye la esperanza que proyecta el comportamiento hacia el futuro (Castells, 2012: 30-31). En el caso de este grupo, las experiencias individuales se politizaron y fueron tejiendo una red que generó una conexión con otras mujeres, quienes desde diversas latitudes de Brasil construyeron la esperanza que les permitió imaginar un país con un futuro democrático. incluyente y sin fascismo.
Ante su éxito en Facebook, las represalias no tardaron en llegar. El 16 de septiembre, el grupo fue hackeado, su imagen y nombre fueron alterados en apoyo al candidato Jair Bolsonaro. Gracias al apoyo de Facebook, las administradoras lograron recuperarlo $\mathrm{y}$, posteriormente, ratificaron su compromiso con la defensa de la democracia en Brasil.

Otra maniobra en contra de los objetivos del grupo, y en favor del candidato del PSL, consistió en copiar su estrategia. Se crearon grupos como "Mujeres Con Bolsonaro \# 17 (OFICIAL)" que en septiembre de 2018 logró reunir 403945 miembros, es decir, sólo un tercio del volumen de quienes en el mismo periodo integraron Mujeres Unidas contra Bolsonaro (Becker, 2018). Otra iniciativa fue "Mujeres unidas A FAVOR de Bolsonaro", con 48346 miembros, cuyos contenidos fueron compartidos en otras páginas de apoyo a este candidato con un mayor número de seguidores, como "Apoyemos la Operación Lava Jato-Juez Sérgio Moro”, página que cuenta con más de un millón de seguidores (Becker, 2018). Asimismo, se colocó como tendencia (trending topic) en Twitter el hashtag \#MujeresConBolsonaro (\#MulheresComBolsonaro), sin embargo, después se descubrió que esta hazaña se logró con perfiles de hombres (Becker, 2018).

De acuerdo con Carolina Matos (2017: 423) existen tres momentos clave en la historia contemporánea del feminismo brasileño. El primero en la década de 1970 , durante la dictadura militar, cuando surgió el movimiento feminista; el segundo, en los años de redemocratización, cuando el feminismo se pluralizó; y, el tercero, en los inicios del siglo xxI, cuando se multiplicaron los campos feministas, con prácticas plurales y un flujo discursivo horizontal.

Lo paradigmático de Mujeres Unidas contra Bolsonaro radica en que la pluralización de los feminismos que caracteriza a las etapas anteriores encuentra unidad en este movimiento que se origina a partir de un grupo en Facebook y que visibiliza la centralidad y trascendencia de una agenda feminista interseccional para los regímenes democráticos contemporáneos, por lo que podríamos estar ante una cuarta inflexión importante dentro del feminismo brasileño.

\section{Del ciberfeminismo al tecnofeminismo interseccional}

Para sustentar de qué manera el grupo Mujeres Unidas contra Bolsonaro encarna un tecnofeminismo interseccional es necesario partir de una breve genealogía del activismo feminista en y desde internet. El ciberfeminismo es la primera corriente que desde finales 
de la década de 1980 inaugura esta tendencia y se caracteriza por una posición optimista respecto al papel de las tecnologías de la información y la comunicación (TIC) para acortar las desigualdades de género.

Amparo Romero Sánchez (2014: 159) establece que el ciberfeminismo se inició en Australia "como un movimiento artístico de mujeres cuyo objetivo consistió en subvertir la identidad femenina en la red, espacio idóneo para esta tarea por su carácter flexible y abierto". Si bien la fundamentación teórica del movimiento ciberfeminista se encuentra en el libro Ceros + Unos. Mujeres digitales + la nueva tecnocultura de Sadie Plant, el ciberfeminismo encontró un hilo conductor significativo en el Manifiesto para cyborgs de Donna Haraway, en el que plantea un punto de vista optimista respecto a la tecnología, al mismo tiempo que rechaza el esencialismo y la tecnofobia de diversas corrientes feministas de las décadas de los setenta y ochenta (Romero Sánchez, 2014: 157, 159-160).
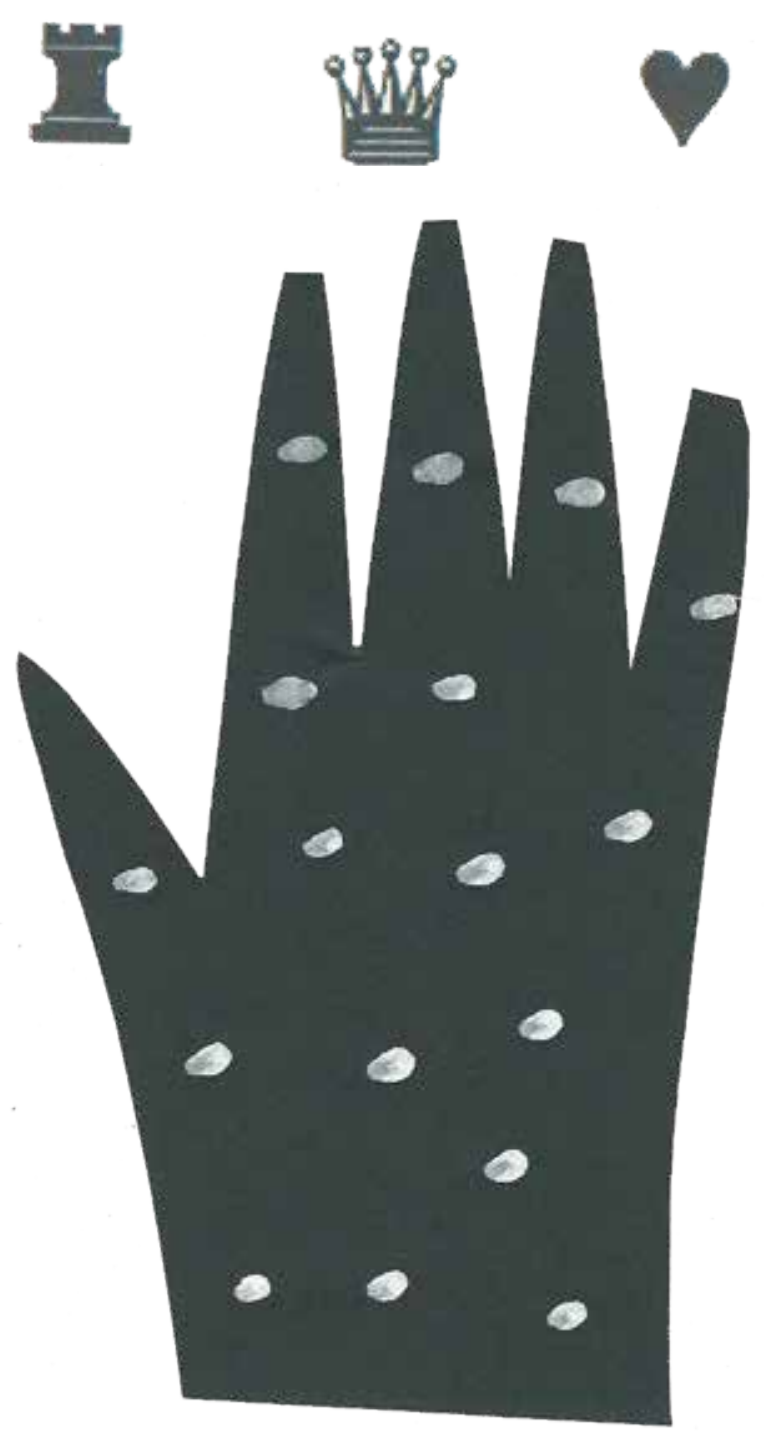

Por lo tanto, la principal crítica al ciberfeminismo radica en que al asumir que las tecnologías por sí mismas -sin algún tipo de acción política-son liberadoras para las mujeres, carece de una visión crítica con enfoque de género sobre hasta qué punto la tecnología puede ser el instrumento idóneo para la emancipación (Romero Sánchez, 2014: 163, 165).

En este contexto de crítica al ciberfeminismo surge el tecnofeminismo, que representa el siguiente eslabón que da forma a esta genealogía. Este término fue creado por Judy Wajcman, y con él pretende establecer una vía "entre el optimismo utópico y el fatalismo pesimista" que permeó las teorías feministas de la tecnología (Wajcman, 2006: 15). Desde una postura constructivista, establece que la tecnología es un producto sociotécnico "conformado por las condiciones de su creación y uso", por lo que (la tecnología) "es, al mismo tiempo, fuente y consecuencia de las relaciones de género" (Wajcman, 2006: 56, 166).

Para Wajcman (2006: 184), al vincular las relaciones de producción y consumo de la tecnología, "el tecnofeminismo no sólo analiza minuciosamente las metáforas emancipatorias, sino que también trata de equilibrar este análisis con un énfasis equivalente en las realidades materiales de la producción y la utilización de una determinada tecnología".

En el caso de una tecnología como la que representan las redes sociodigitales, como Facebook, esta perspectiva tecnofeminista permite atender tanto a las posibilidades emancipatorias del activismo desde internet como a sus realidades materiales y estructurales fuera de línea, lo cual constituye un punto esencial desde el que interesa visibilizar el tecnofeminismo interseccional que aquí se plantea, ya que a partir de esta relación constructivista entre lo que sucede en línea y fuera de línea, es decir, entre internet y la calle, teje puentes con la tecnopolítica que traza Javier Toret.

Desde su posición, la tecnopolítica pone de relieve "una capacidad colectiva de utilización de la red para inventar formas de acción que pueden darse o partir en la red pero que no acaban en ella" (Toret, 2013: 20-21) y puede definirse como:

El uso táctico y estratégico de las herramientas digitales para la organización, comunicación y acción colectiva [...] Desde la perspectiva del sistema red, la tecnopolítica puede redescribirse como la capacidad de las multitudes conectadas, de los cerebros y cuerpos conectados en red, para crear y automodular la acción colectiva [Toret, 2013: 20].

Javier Toret precisa que el concepto de multitud conectada es "la capacidad de conectar, agrupar y 
sincronizar, a través de dispositivos tecnológicos y comunicativos y en torno a objetivos, los cerebros y cuerpos de un gran número de sujetos en secuencias de tiempo, espacio, emociones, comportamiento y lenguajes" (2013: 20). Sin embargo, es importante enfatizar que, desde su visión, las redes no sólo construyen o coordinan la acción colectiva, sino que sirven "para tejer el sentido de la propia acción y para crear un impulso constituyente en un marco de acción, pensamiento y estructuración social (Toret, 2013: 19).

Dicha construcción de sentido sobre la acción se produce a través de procesos de comunicación que, siguiendo a Castells (2012: 23), dan cuenta de un ejercicio de poder desde la resistencia, que es posible gracias a la construcción de significados, desde donde se proyectan y se visualizan otras formas de estar juntos, otras normas y valores, así como otras formas de organización de las instituciones sociales.

En síntesis, el tecnofeminismo interseccional que encarna un grupo como Mujeres Unidas contra Bolsonaro en una plataforma tecnocultural (Van Dijck, 2016) como Facebook parte del enfoque constructivista de la articulación en línea y fuera de línea (online / offline) de Wajcman y teje puentes hacia las inflexiones teóricas sobre la acción colectiva y las multitudes conectadas entre internet y la vía pública que establece Toret a propósito de la tecnopolítica, para ejercer el poder desde la resistencia a través de la construcción de significados que ponen en circulación mujeres que personifican diversas desigualdades.

Desde este punto de vista, el tecnofeminismo interseccional de Mujeres Unidas contra Bolsonaro es parte del "devenir feminista o feministización de las movilizaciones sociales, que va más allá de las mujeres o las feministas" (Rovira Sancho, 2018: 224), ya que la agenda interseccional que visibiliza es un manifiesto contra un sistema neoliberal desde el que se ancla el neoconservadurismo político-evangélico y posfascista presente en Brasil.

\section{Coordenadas metodológicas}

Para analizar las prácticas tecnofeministas del grupo Mujeres Unidas contra Bolsonaro se diseñó una estrategia cimentada en la etnografía digital, la cua replantea los principios del método etnográfico para el estudio de las prácticas sociales en internet (Hine, 2015). Concretamente, se eligió la técnica de la observación etnográfica en su modalidad no participante, la cual tuvo lugar del 6 al 28 de octubre de 2018, es decir, desde un día antes de la primera vuelta del proceso electoral y hasta el día de la segunda vuelta, cuando Jair Bolsonaro fue electo como presidente con 55\% de los votos, derrotando a Fernando Haddad, candidato del Partido de los Trabajadores (PT).

Para llevar a cabo un proceso de observación sis-

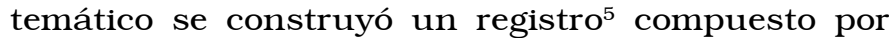
301 publicaciones. Se examinaron alrededor de $14 \mathrm{pu}-$ blicaciones por día, con excepción de las fechas en las que se realizó la primera y segunda vuelta de las elecciones, cuando la página cerró sus publicaciones "con la intención de preservar la integridad jurídica del grupo, tanto de sus integrantes como de todo el conjunto administrativo".

En el proceso de observación se perfilaron las siguientes categorías en una posición central: prácticas del activismo en redes, prácticas del activismo en las calles, politización de la experiencia desde las narrativas de las mujeres, identidades que encarnan diversas desigualdades e imaginarios sobre el presente, pasado y futuro de Brasil, y gracias a estas categorías fue que se formuló la perspectiva sobre el tecnofeminismo interseccional que aquí se expone.

\section{Anclajes del tecnofeminismo interseccional en Brasil ante la amenaza fascista}

Para trazar las coordenadas del feminismo interseccional que se produjo desde el grupo Mujeres Unidas contra Bolsonaro es fundamental partir de una visualización del mapa de hashtags que, como campos discursivos de acción (Alvarez, cit. en Branco de Castro Ferreira, 2015), articularon sus prácticas tanto en internet como en el espacio público.

Si bien el uso de los hashtags, o etiquetas, surgió en Twitter en 2007, actualmente este sistema de agrupación y clasificación es empleado en otras redes sociodigitales como Facebook. De acuerdo con Costa Moura (en Silva Reis, 2017: 3) fueron usados por primera vez con la finalidad de articular movimientos políticos en las elecciones iranianas de 2009-2010.

A continuación se presenta un esquema con los hashtags que, en tanto campos discursivos de acción, marcaron la pauta de las conversaciones, los objetivos y la apuesta del movimiento iniciado en Mujeres Unidas contra Bolsonaro. Dicho esquema responde a cinco categorías: 1) el proceso electoral-coyuntura

5 Los pormenores sobre los fundamentos y las técnicas que dan forma al método de la etnografía digital, así como el procedimiento para construir un registro de observación, se explican a detalle en Bárcenas Barajas y Preza Carreño (2019). 
que marca esta politización tecnofeminista-, 2) la resistencia feminista, 3) Brasil contra el posfascismo, 4) Fernando Haddad, y 5) Jair Bolsonaro.

Por ser un grupo que se posicionó de manera abierta contra este candidato, es mayor la cantidad de hashtags en apoyo a Haddad (PT). Además, en algún momento de su organización acordaron no nombrar a Bolsonaro para no otorgarle mayor visibilidad (véase fig. 1).

Las siguientes fotos permiten tejer un puente analítico sobre la forma en que las protestas contra Jair Bolsonaro se llevaron de internet a la vía pública. La primera ilustra la polarización que generó su candidatura, así como las protestas en su contra a través de la sentencia "él no" (ele não). La segunda permite destacar el uso de la frase ¡Él nunca! (Ele Nunca!) como un complemento que en Facebook (véase figura 1) y en las calles, reforzó la consigna ¡Él no! (\#EleNão).

\section{Diversidades y desigualdades que encarnan el tecnofeminismo interseccional}

Las identidades y voces de protesta que se manifestaron en internet y en las calles a través de Mujeres Unidas contra Bolsonaro hicieron visibles las múltiples formas en las que la desigualdad se encarna en las mujeres brasileñas. Además del género -que produce un primer esquema de desigualdad- la raza, la etnia, la orientación sexual, la identidad de género y la religión completaron este mosaico de desigualdades, que las coloca en condiciones de pobreza y las expone al racismo, el estigma y la discriminación.

En este contexto fue que mujeres: negras, indígenas, de la tercera edad, lesbianas, bisexuales, trans, evangélicas (de izquierda o feministas) y umbandistas,

Figura 1

Hashtags del tecnofeminismo interseccional

Proceso electoral

\#Eleições2018 \#VotoSim, \#NuloNão \#BrancoNão \#DebateSim

\section{Resistencia feminista}

\#MulheresContraBolsonaro

\#MulheresAFavorDaDemocracia

\#MulheresUnidasComHaddadEManu 13

\#JuntasSomosMaisFortes

\#ALutaContinua

\#MulheresUnidasJamaisSeraoVencidas

\#Resistencia

\#MarielePresente

\section{Fernando Haddad}

\#Haddad \#FernandoHaddad \#EleSim \#ÉHaddadSim \#HaddadSim \#HaddadEleSim \#HaddadManuela13 \#HaddadEManu \# 13HaddadSim \#Haddad 13

\#HaddadPresidente

\#Haddad13Presidente \#HaddadPresidente 13

\#HaddadPresidente 13PT

\#HaddadPresidente2018

\#ProfessorHaddadPresidente

\#Haddad2018EuVoto \#Haddad2018

\#HaddadBrasil \#Brasil 13

\#H13 \#VotoHaddad

\#HaddadSim 13PelaDemocracia

\#HaddadDemocracia \#HaddadSaude

\#HaddadSeguranca

\#Haddad13PelaVidaPelaPaz

\#SomosTodosHaddad \#FechadoComHaddad

\#AgoraÉHaddad \#ViraVotoProHaddad
Brasil contra el posfascismo

\#FascistasNãoPassarão

\#DictaduraNuncaMais

\#TorturaEDictaduraNuncaMais

\#PorFavorDictaduraNão

\#ViolênciaNão

\#DemocracíaSim

\#VivaADemocracia

\#AmorSim

\#LibertadeSim

\#LulaLivre

\#HoraDaVirada

\#OBrasilFelizDeNovo

Jair Bolsonaro

\#EleNão

\#EleNunca

\#NotHim

\#BolsonaroNão

\#EleJamais

\#EleNever

\#TodosContraEle

\#BoçalnaroNão

\#BoçalnaroNunca

\#ForaFacista

\#ForaBolsonaro

\#BolsonaroAbominavel

\#Caixa2doBolsonaro

\#RedegloboCaixa2doBolsonaro

\#CassaçãoDoBolsonaro

\#ImpugnaJá

\#B17Não

\#Fujão

Fuente: Elaboración propia. 


\section{Foto 1}

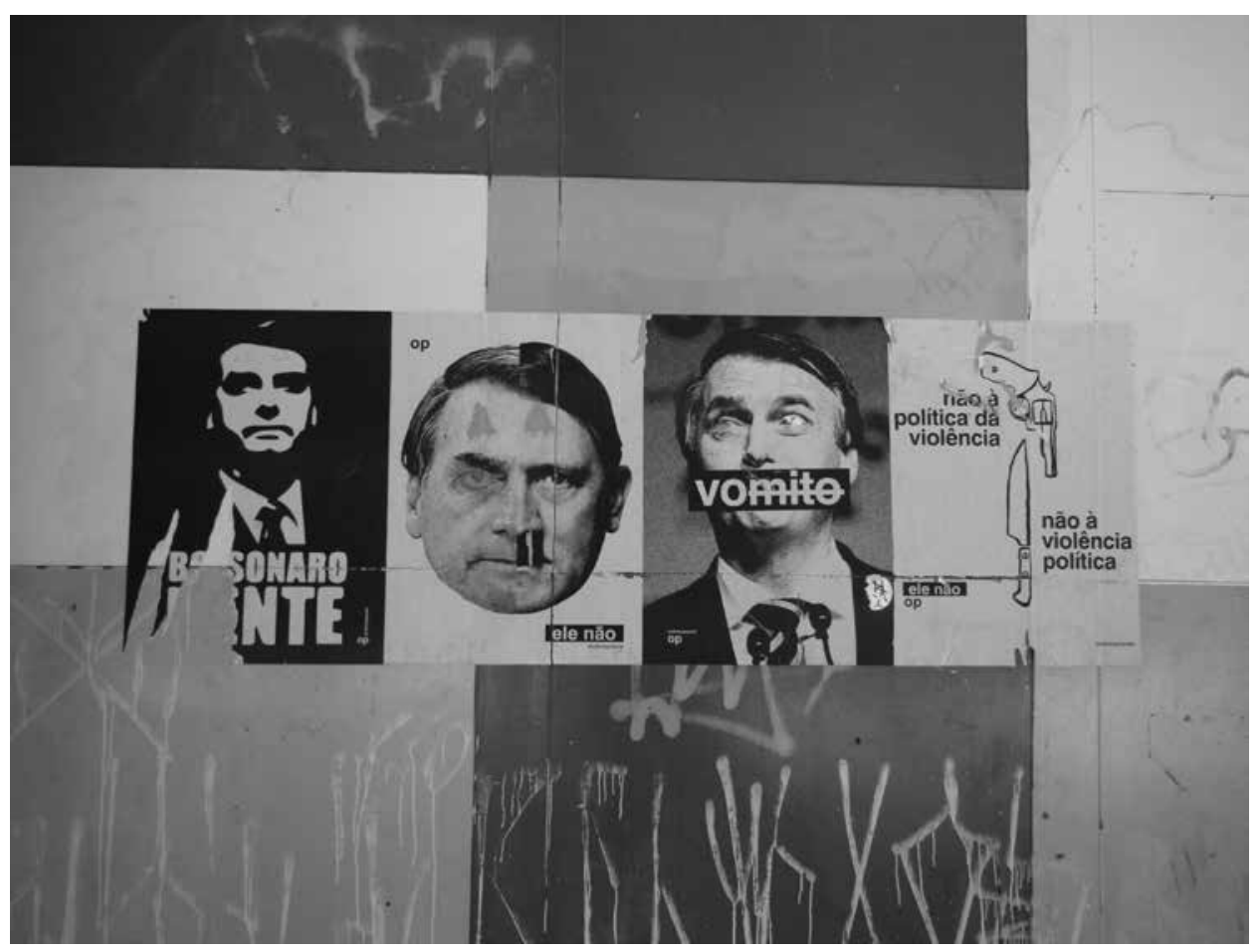

Protestas en las calles de São Paulo, con la consigna "él no" (ele não) (Enero de 2019, foto de la autora).

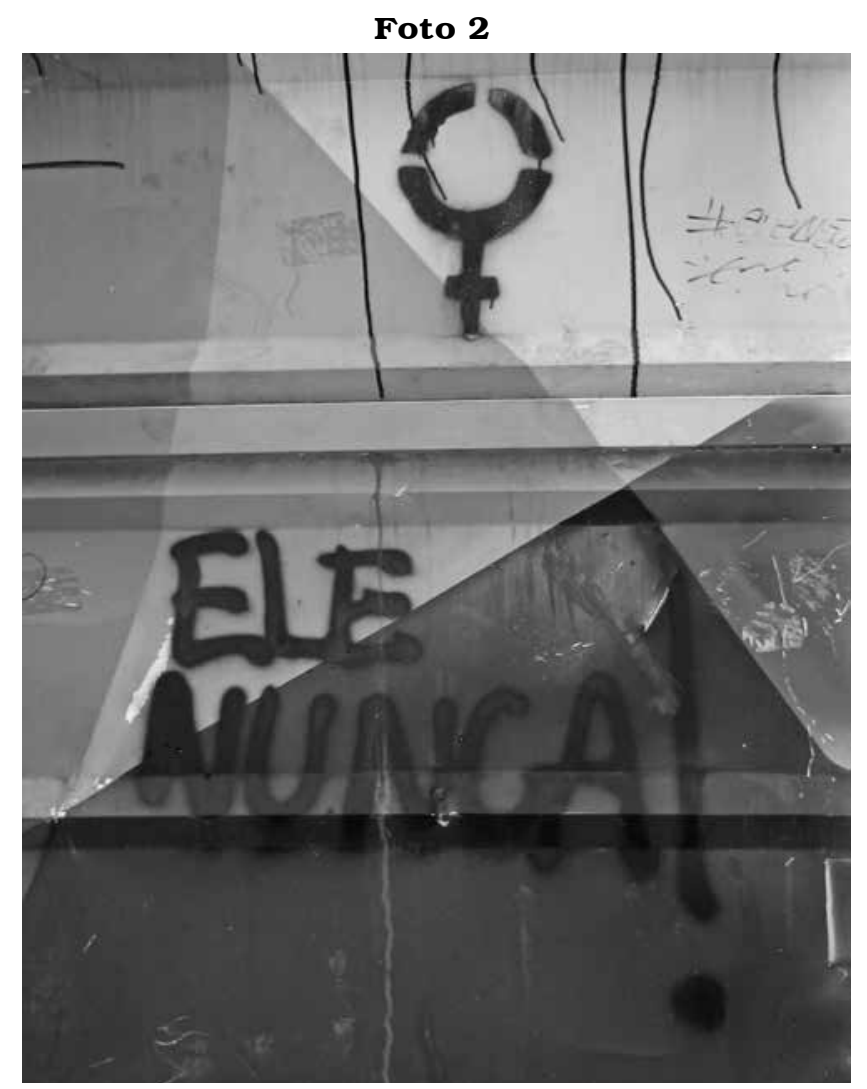

Ele Nunca! (Él nunca), São Paulo

(Enero de 2019, foto de la autora). 
levantaron la voz en las redes sociodigitales y en el espacio público, dando paso a la conformación de un tecnofeminismo interseccional, que hizo visible una agenda feminista que muestra identidades atravesadas por dos o más formas de desigualdad y, por consiguiente, expuestas a dos o más formas de vulnerabilidad, estigma o discriminación. Este tecnofeminismo interseccional encontró un punto de convergencia en el posicionamiento colectivo contra el posfascismo y en favor de la democracia.

Por la propia composición de la población brasileña, las mujeres negras fueron las que evidenciaron de mejor modo las diversas desigualdades que de manera interseccional encarnan. En este grupo en Facebook y en las calles se hicieron presentes mujeres negras trans, mujeres negras bisexuales y mujeres negras de la tercera edad. El puño arriba y el hashtag \#EleNão fueron símbolos importantes para expresar la resistencia desde sus identidades. Hubo otros símbolos de resistencia, como la imagen de una mujer negra de edad avanzada quien portaba una calcomanía de apoyo a Haddad y un pin con el hashtag \#EleNão.

Asimismo, la orientación sexual y la identidad de género hicieron visibles fuertes condiciones de vulnerabilidad para las mujeres. En los medios de comunicación tomó gran visibilidad el caso de una lesbiana de 19 años que fue agredida en la calle un día después de la primera vuelta de las elecciones. Le grabaron una suástica en las costillas con un arma punzocortante, por el simple hecho de llevar una bandera arcoíris, emblema del movimiento LGBT (lésbico, gay, bisexual y transgénero), en su mochila. Cuando se publicó en el grupo este hecho, sus integrantes expresaron su enojo, horror, coraje, tristeza, miedo, terror e incredulidad. Algunas pidieron ser libradas del "Hitler brasileño" y otras hicieron un llamado a oponerse explícitamente y detener a quienes practicaran actos violentos contra las personas LGBT.

De igual modo se compartió en Facebook la transmisión en vivo de una mujer negra transgénero en una situación de riesgo ante las ofensas y amenazas de los seguidores de Bolsonaro. En el video se observa que un hombre (que portaba una playera de apoyo a este candidato) y sus familiares la insultan y le gritan; otras personas que transitan en sus carros se les unen tocando el claxon, se burlan de Haddad y enaltecen a Bolsonaro. En su testimonio ella escribió: "estoy realmente asustada, la gente nunca piensa qué va a pasar con nosotros [...] en el momento que sentí miedo empecé a grabar [...] voy a luchar y resistir [...] hoy me juzgan y me ofenden, ¿mañana me matan?”. A partir de esta situación se buscó hacer conciencia sobre las implicaciones del voto nulo en la segunda vuelta de las elecciones y la necesidad de convencer a los indecisos de votar por Haddad.

En el grupo Mujeres Unidas contra Bolsonaro también se hicieron visibles agrupaciones de mujeres judías, católicas y adventistas que, a partir de su identidad religiosa, tanto en internet como en la vía pública se posicionaron abiertamente contra Bolsonaro. Enfatizaron un \#EleNao argumentando que su fe está en contra del fascismo, del regreso de una dictadura y de la tortura, por lo que están en favor de la democracia y la paz.

Sin embargo, se puede considerar que son las mujeres umbandistas y evangélicas (de izquierda y feministas) las que encarnan una desigualdad interseccional, ya que, además de ser mujeres, se alejan de las posturas mayoritarias de sus religiones. Por el particular contexto brasileño, marcado por una fuerte presencia evangélica tanto en creyentes como en actores políticos, es importante profundizar en la resistencia que se produjo desde esta identidad religiosa. De acuerdo con Santos (2018) las mujeres evangélicas fueron las que de manera más evidente expresaron su apoyo a Haddad al sentirse heridas o amenazadas con las palabras de Bolsonaro; además señalaron que los evangélicos no son fascistas, sino que se han dejado llevar por los líderes de sus Iglesias y por las noticias falsas relacionadas con lo que se denominó el kit gay, ${ }^{6}$ dos elementos que influyeron en el voto por Bolsonaro.

Como parte de esta politización evangélica contra la candidatura de Bolsonaro, un grupo de mujeres evangélicas, de denominaciones metodistas, bautistas, presbiterianas, anglicanas y luteranas, entre las que destaca la conocida teóloga feminista Nancy Cardoso, lanzaron un manifiesto acompañado por el hashtag \#NaoEmNossoNome, en el que puntualizaron:

Es con preocupación que nosotras, mujeres evangélicas, vemos ganar fuerza en estas elecciones de discursos violentos que se alimentan de odios y resentimientos. Desafortunadamente, parte de esos discursos surgieron en un ambiente religioso y evangélico [...] En el golpe del 64 y durante la dictadura militar, buena parte del movimiento evangélico, inclusive diversas denominaciones, dieron apoyo y homenajearon a los golpistas y dictadores. Mientras la dictadura brasileña torturaba y mataba opositores, parte de las Iglesias protestantes silenciaban

\footnotetext{
6 Nombre que se le otorgó a un conjunto de materiales de educación sexual que fueron diseñados cuando Haddad era ministro de Educación.
} 
y expulsaban las voces libertarias y democráticas que osaran levantarse contra el régimen [...] Afirmamos como evangélicas que no concordamos con las posiciones de líderes y religiosos que dicen hablar en nuestro nombre o en defensa del evangelio para apoyar la candidatura de Jair Bolsonaro. Ningún autoritarismo se puede sustentar en nombre de los evangélicos o de nuestras Iglesias o con el pretexto de estar en consonancia con el evangelio del Reino. El evangelio del Reino tiene que ver con justicia, paz, alegría. ${ }^{7}$

Aparte de este manifiesto se compartieron otras acciones comandadas desde disidencias evangélicas en contra de la candidatura de Bolsonaro, como las convocadas por el Frente Evangélico por el Estado de derecho, que organizó varios actos en el espacio público, oponiéndose al fascismo y en favor de la democracia, portando pancartas con consignas como la siguiente: "sigo a Cristo y creo que el amor vence al odio". También mantuvieron su politización contra la candidatura de Bolsonaro en sus redes sociodigitales, mostrando testimonios de pastores evangélicos de denominaciones metodistas, bautistas, presbiterianas, anglicanas y luteranas, o de personas adscritas a estas Iglesias, quienes expresaban sus motivos para no votar por él.

A partir de este tipo de publicaciones en el grupo Mujeres Unidas contra Bolsonaro se expuso la relevancia de las mujeres evangélicas para debilitar la candidatura del aspirante del PSL. Propusieron acercarse a sus amigos de la Iglesia y desmentir en WhatsApp las noticias falsas en contra de Haddad. Sin embargo, en paralelo, varias mujeres evangélicas expresaron su desilusión al no poder convencer a otros evangélicos de desistir en su voto por Bolsonaro.

\section{Tecnofeminismo interseccional contra el posfascismo $y$ en favor de la democracia}

Un contundente posicionamiento contra el posfascismo $^{8}$ y en pro de la democracia fue lo que marcó la politización del grupo Mujeres Unidas contra Bolsonaro, cuyas integrantes asumieron que sus demandas y agendas interseccionales sólo podrían encontrar resonancia en un Estado democrático.

Las principales acciones en redes sociodigitales que dieron forma a este tecnofeminismo interseccional fueron: cambiar sus fotos de perfil con un marco de imagen en favor de Haddad, seguir a este candidato en sus otras redes sociales -sobre todo Facebook y Twitter-, militar apoyando a Haddad desde WhatsApp, utilizar el meme como táctica política para visibilizar y generar conciencia sobre los peligros de la llegada de Bolsonaro a la presidencia y, las de mayor trascendencia: generar una estrategia de convencimiento para que quienes pensaran anular su voto no lo hicieran y se lo dieran a Haddad, denunciar páginas con noticias falsas y viralizar hashtags.

La estrategia de convencimiento para cambiar la intención de voto nulo por uno hacia Haddad implicó acordar encuentros dialógicos con familiares, vecinos y amigos para reflexionar sobre la ventaja que representarían los votos en blanco para Bolsonaro y los peligros de su llegada al poder. En el grupo, cada testimonio sobre el convencimiento de voto por Haddad entre sus redes cercanas fue vivido con gran entusiasmo, así como con una reflexión sobre la relevancia de olvidar sus inconformidades con el PT -partido político de izquierda que llevó a la presidencia a Luiz Inácio Lula da Silva y a Dilma Roussef- ya que lo más trascendente era que Bolsonaro no ganara.

Asimismo, en momentos concretos de las campañas acordaron viralizar hashtags con diferentes intenciones. Hashtags como \#Haddad13EleSim \#Haddad13, \#HaddadSim fueron trending topic en momentos clave de la campaña de este candidato. De igual modo, al enterarse que Bolsonaro no asistiría a los debates presidenciales, se viralizaron en diferentes redes sociales hashtags con los que se pedía su presencia: \#naovoto semdebate \#VemProDebate \#QueroDebate \#Prodebate.

El 18 de octubre se dio a conocer en los medios de comunicación brasileños que un grupo de empresarios había gastado 12 millones para distribuir masivamente a través de WhatsApp noticias falsas desacreditando al PT, lo cual beneficiaba muchísimo la candidatura de Bolsonaro. Por lo tanto, se propusieron viralizar el hashtag \#Caixa2doBolsonaro, el cual alude a esta segunda fuente de recursos para su campaña. En gran parte, dichos mensajes de WhatsApp contenían noticias falsas acerca del kit gay, tema sobre el que se generó la campaña de desinformación más intensa y con grandes repercusiones en contra de Haddad. En este ambiente, una práctica esencial de las integrantes del grupo Mujeres Unidas contra Bolsonaro consistió en desmentir esta información en sus redes cercanas y denunciar páginas con noticias falsas.

El 27 de octubre, un día antes de las elecciones, una chica preguntó en el grupo “¿Quién está despierta militando, haciendo campaña para Haddad y buscando

\footnotetext{
Véase manifiesto completo en Mujeres Evangélicas en Defensa de la Democracia, s/f.

Enunciado desde la voz de las mujeres como fascismo.
} 
dar la vuelta a las votaciones?" La publicación alcanzó 23 mil reacciones (20 mil me gusta [likes], $2800 \mathrm{me}$ encanta, 56 me sorprende, 20 me divierte) así como 9200 comentarios. Las integrantes del grupo se hicieron presentes con cadenas de hashtags y confirmaron su militancia a esas horas.

Estas estrategias en internet se intersectaron con un conjunto de movilizaciones en las calles. Este es un hecho de gran trascendencia si consideramos que la tecnopolítica, perspectiva de la que se nutre el tecnofeminismo interseccional que aquí se ha delineado, implica activismo tanto en línea como fuera de línea, multitudes conectadas a través de estados de ánimo colectivos en estas dos dimensiones entrelazadas.

El grupo convocó a un primer acto de protesta en contra de la candidatura de Bolsonaro para el sábado 29 de septiembre, el cual tuvo lugar en 40 ciudades de 26 estados de Brasil, además de otras urbes del exterior como Barcelona, Berlín, Lisboa, Milán, Ciudad del Cabo, Nueva York, Viena y México, gracias a la convocatoria del Colectivo Regina de Sena México-Brasil contra el Golpe. Estas manifestaciones fueron trending topic en Twitter durante ese día.

De acuerdo con Jiménez et al. (2018) tan sólo en São Paulo este acto contra Bolsonaro reunió alrededor de 150 mil personas y es la mayor protesta popular registrada desde septiembre de 2016, cuando los brasileños salieron a protestar contra Michel Temer, después del proceso de destitución (impeachment) de Dilma Rousseff. Además, durante ese fin de semana, por cada búsqueda en Google de "ele sim" (él sí) se realizaron seis para "ele não" (él no) y por cada post pro Bolsonaro en páginas en Facebook, cuatro fueron hechos en su contra (Ramos, 2018).

En el contexto de las protestas del sábado 29 de septiembre, Mujeres Unidas contra Bolsonaro dieron a conocer un manifiesto de oposición a la candidatura de Jair Bolsonaro y contra el posfascismo. En él señalaron su postura de rechazo al discurso de odio del candidato hacia los negros, indígenas, homosexuales y los derechos de las mujeres; a su voto como diputado en favor del congelamiento de gastos en salud, educación y asistencia social por 20 años; a su defensa a la dictadura militar, así como a un proyecto de seguridad pública basado en la militarización.

Dicho manifiesto -cuyo lema es "Por la igualdad, libertad, derecho y una vida sin violencia"- inicia destacando las diversidades y desigualdades que de manera interseccional atraviesan a las integrantes del grupo.
Somos mujeres, millones y diversas. Somos brasileñas y migrantes. Jóvenes y de cabellos blancos. Negras, blancas, indígenas. Trans y travestis. Somos LGBT, amamos hombres, mujeres o ambos. Casadas y solteras. Madres, hijas, abuelas. Somos trabajadoras, amas de casa, estudiantes, artistas, funcionarias públicas, pequeñas empresarias, comerciantes, sin techo, sin tierra. Empleadas y desempleadas. Mujeres de diferentes religiones y sin religión. Estamos hoy juntas y de cabeza erguida en las calles de todo Brasil porque un candidato a la presidencia del país, con un discurso fundado en el odio, en la intolerancia, en el autoritarismo y en el atraso, amenaza nuestras conquistas y nuestra ya difícil existencia. Estamos en la calle porque su programa político-económico es un retroceso, una reproducción empeorada de las terribles políticas de Temer [...] Por eso decimos: ¡Él no! ¡Ni sus hijos! ¡Bolsonaro nunca! ¡Fascismo no!

Una segunda manifestación masiva contra la candidatura de Bolsonaro y en apoyo a Haddad fue convocada para el sábado 20 de octubre por Mujeres Unidas contra Bolsonaro y otros colectivos como el Frente Brasil Popular y el Frente Pueblo sin Miedo. Ese día los brasileños salieron a las calles en 29 ciudades de 15 estados de Brasil.

Otra práctica tecnopolítica importante fuera de las redes sociodigitales fue la reunión que la creadora del grupo y ocho de sus administradoras tuvieron con Manuela D'Ávila, candidata a la vicepresidencia por el PT. En esa reunión, las representantes del grupo le entregaron un pliego petitorio, el cual ella firmó y más tarde publicó en sus redes sociodigitales con el siguiente mensaje: "Conocí a estas mujeres maravillosas, que son lucha, dulzura y resistencia [...] firmé la carta entregada por ellas con la propuesta para mejorar la vida de las mujeres brasileñas". En la fotografía que acompaña esta publicación todas las integrantes del grupo portan en su ropa el hashtag \#EleNão.

Mujeres Unidas contra Bolsonaro fue un gran escenario para dar a conocer los diferentes actos organizados en el espacio público en contra de la candidatura de Bolsonaro o en favor de Haddad. Hubo varias manifestaciones en plazas públicas, universidades, playas, estaciones del metro, centros comerciales, etcétera que no fueron organizadas por ellas, pero a las cuales algunas de sus integrantes se unieron. Así lo dejan ver las publicaciones en las que ellas se reconocen como parte de esas protestas. Asimismo, los espacios privados jugaron un papel fundamental, sobre todo en relación con la estrategia de cambiar

9 El manifiesto completo se puede consultar en Brasil de Fato, 2018. 
entre sus redes cercanas la intención de anular el voto por uno en favor de Haddad.

\section{Politización de la experiencia y estados de ánimo colectivos}

Para Javier Toret (2013: 35) un elemento clave de la tecnopolítica son las multitudes conectadas a través de redes de información y de comunicación, pero también de estados de ánimo colectivos, que son necesarios para empoderarse y posibilitar comportamientos que lleven a tomar las riendas de asuntos comunes.

En otras investigaciones, como la de Navarro, Martínez-García y Vialás Fernández (2018: 297), se ha destacado además la centralidad de Facebook para la construcción de una concepción de sororidad que se crea entre grupos de mujeres que comparten espacios en línea y fuera de línea. En este contexto, en el presente apartado interesa destacar de qué manera la construcción de estados de ánimo colectivos medió el tecnofeminismo interseccional que se articuló desde Mujeres Unidas contra Bolsonaro.

De acuerdo con Toret:

La dimensión performativa de la tecnopolítica se alcanza en la medida de la energía en red que las personas son capaces de generar para una acción colectiva. Primero se visualiza y se lanza una idea de acción colectiva, se hace el trabajo de extenderla, se cree colectivamente en algo que se está creando y va adquiriendo vida en la medida que la interacción social se lo apropia [Toret, 2013: 52].

Esta descripción hecha por Toret explica la fundación y consolidación del grupo Mujeres Unidas contra Bolsonaro, en el cual las brasileñas tomaron las redes como vía de politización, para construir desde su narrativa un lugar de enunciación con fines persuasivos de oposición a la candidatura de Bolsonaro, la cual estuvo enclavada en un neoconservadurismo evangélico (predominantemente pentecostal y neopentecostal) y una ideología posfascista.

Dicha politización de la experiencia fue elemento decisivo del activismo que emprendieron en las redes y en las calles, por lo que recurrieron a las narrativas de otras mujeres para construir un sentir colectivo sobre la esperanza, desde la que se gestó la resistencia y se mantuvo el trabajo colectivo y el apoyo a Haddad hasta los últimos días previos a la segunda vuelta en las elecciones. Fue común encontrar frases como "estamos juntas", palabras de aliento y orgullo por encarnar la resistencia que, en ese momento, más que nunca, se requería para luchar contra el posfascismo. Tenían claro que no podían demostrar miedo ni debilidad al enemigo. Reconocieron ser parte de un grupo de más de cuatro millones de mujeres que estaba haciendo la diferencia y se motivaron para no rendirse.

Asimismo, otra estrategia central para apropiarse del sentimiento de esperanza desde el que se articularon sus acciones y agendas de trabajo en las redes y en las calles consistió en olvidar las siglas partidistas y pelear por un país justo, amoroso y sin odio.

Como ya se mencionó, una práctica esencial de este tecnofeminismo interseccional fue convencer a personas cercanas de votar por Haddad. Estos logros fueron compartidos con esperanza y alegría en el grupo. El 13 de octubre, una de sus integrantes publicó su hazaña: acababa de conseguir un voto para Haddad, y adjuntó una imagen del candidato, acompañada de la frase: "deja el odio de lado y ven a amar"; la publicación tuvo 59 mil reacciones (41 mil me gusta, $15 \mathrm{mil}$ me encanta, 1700 me divierte) y 6800 comentarios. Y otra mujer del grupo señaló:

A cada mujer que veo en este grupo desistiendo del voto nulo para expresar su decisión de votar por Haddad (así sea sin gustar del Pт) [...] es como una luz que asciende, una esperanza. ¡Gracias chicas, ustedes están por encima de todo, humanas! Este grupo ha sido como un abrazo en los días difíciles. Vamos que aún hay esperanza me \#EleNão \#EleNunca.

La publicación alcanzó 6400 reacciones $(5$ mil me gusta y 1300 me encanta) así como 1800 comentarios, en los que se adjuntaron imágenes con el lema "no anules tu voto, Brasil necesita de ti", "Digo no a las armas y sí a la vida y el amor". Ya no se habla de estar en favor de algún partido político, sino de salvar la democracia.

Marielle Franco ${ }^{10}$ también se convirtió en un gran símbolo de esperanza, así lo demuestra una de las publicaciones en la que se compartió una imagen con su nombre, creado con el cuerpo de varias mujeres en una calle de Brasil. Este acto fue un símbolo de la memoria y rechazo a las acciones del PSL, partido de Jair Bolsonaro, acusado de destruir la placa homenaje a Marielle en una calle de Río de Janeiro. En la publicación escribieron "Marielle es mucho más grande

${ }^{10}$ Mujer negra, activista, lesbiana, feminista y consejal de Río de Janeiro, asesinada en esta misma ciudad el 14 de marzo de 2018 . 


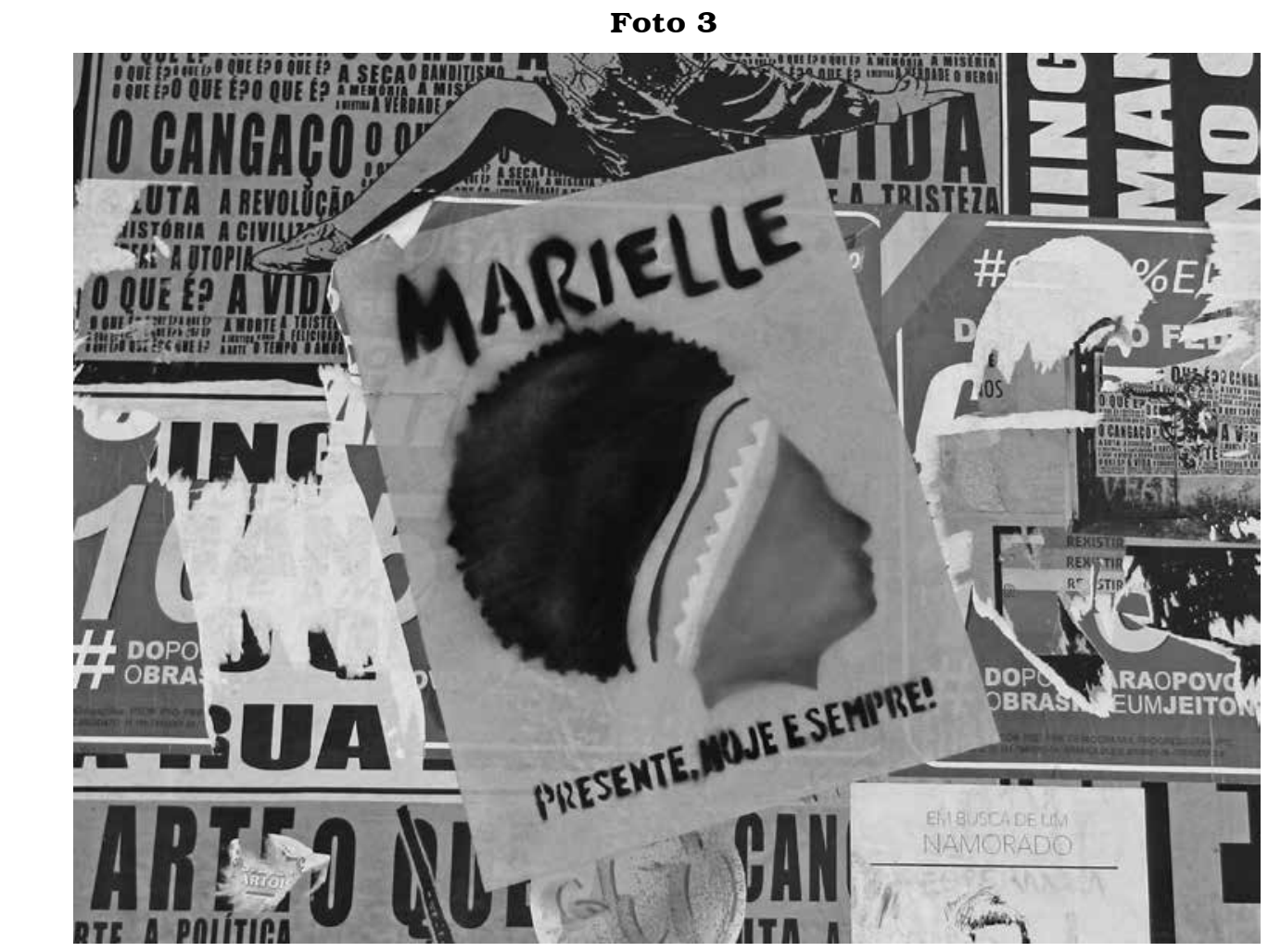

Marielle Franco se convirtió en un símbolo feminista en Brasil, por lo que su imagen, ahora, forma parte de la protesta que se plasma en los muros de ciudades como São Paulo. En esta imagen destaca la leyenda “iPresente hoy y siempre!

(Enero de 2019, foto de la autora).

que una placa con su nombre rota por fascistas. Marielle gigante", mientras que en los comentarios expresaron "Marielle vive", "Marielle está presente", “Todas somos Marielle”.

\section{Imaginarios sobre el pasado, presente y futuro democrático de Brasil}

Las movilizaciones de oposición al posfacismo y en pro de la democracia delinearon un conjunto de imaginarios sobre el pasado, presente y futuro de Brasil, que, a la par de los estados de ánimo colectivos presentados anteriormente, sirvieron como una brújula que permitió conducir hacia un mismo objetivo las acciones que tuvieron lugar tanto en las redes como en la vía pública.

En estos imaginarios fue posible identificar el peso de la dictadura en el pasado reciente de Brasil, así como el proceso de redemocratización gracias a los gobiernos del PT, los cuales hicieron posible que muchos brasileños en condiciones de marginación ter- minaran sus carreras universitarias, compraran una casa o tuvieran apoyos para el campo. En este contexto fue que tanto la dictadura como el reciente proceso democrático -que les permitió mejorar su calidad de vida con acceso a la salud, la educación y conquistar derechos y libertades- se convirtieron en las principales coordenadas de sentido contra la candidatura de Jair Bolsonaro.

El presente se representó a partir de un imaginario sobre la unión de la nación brasileña en lucha por la democracia. Esta unión, desde la perspectiva de las mujeres del grupo, implicaba olvidar las siglas partidistas para pelear por un país justo, amoroso y sin odio. Ante las reservas que algunas mujeres expresaron por Haddad por ser el candidato del PT, una de las integrantes del grupo compartió la siguiente reflexión que hizo eco en el sentir de muchas más: "yo no soy petista, yo voto por la democracia! Haddad 13 y Manu. A veces la gente escoge su candidato de corazón, otras es preciso escoger a quien hace oposición".

Igualmente, los nordestinos dieron paso a un imaginario desde el que se les colocó como "salvadores" de Brasil, ya que en esta región el voto contra Bolsonaro 
fue mayoritario tanto en la primera como en la segunda vuelta de las elecciones. Por ende, fueron representados como parte de una región que con orgullo de sus raíces y de su cultura encarna la resistencia.

Las integrantes del grupo Mujeres Unidas contra Bolsonaro construyeron un imaginario sobre el futuro que concebían para Brasil y que se aleja del proyecto posfascista-bolsonarista. Este imaginario da cuenta de un país democrático que, por su pasado reciente, dice "dictadura nunca más”, lo que buscan es un Brasil laico que también sea de y para las minorías, más equitativo, con iguales derechos y libertades para todos, sin discriminación, sin racismo, con políticas de educación para los jóvenes, sin militarización y sin guerra.

En estas circunstancias, Haddad significó una vía para que este Brasil -representado desde el imaginariofuera posible. En diferentes expresiones de la protesta -mantas, pancartas, imágenes para redes sociodigitales-, fue común encontrar su nombre asociado con la libertad, la igualdad y la fraternidad (LiberHaddade, IgualHaddade, FraterniHaddade).

\section{Reflexiones finales}

El 28 de octubre, día de la segunda vuelta de las elecciones, en el grupo se colocó la imagen de dos brazos tomados de la mano en medio de una rosa blanca, en los bordes se puede leer "Nadie suelta la mano de nadie. Para ese $46 \%$ que luchó sin miedo. Continuaremos juntos contra el fascismo". Desde entonces, Mujeres Unidas contra Bolsonaro ha continuado su lucha en este espacio de resistencia, que ahora se denomina Mujeres Unidas con Brasil y mantiene 2.5 millones de sus integrantes.

Para reconocer su trayectoria, su fundadora Ludmilla Teixeira y la administradora y asesora de comunicación Gisele Figueiredo, fueron invitadas a Ginebra para entregar a la Comisión de Derechos Humnos un dossier de 67 páginas en el que se exponen los relatos sobre la violación de derechos de las comunidades indígenas, negras, quilombola, sin tierra y sin lugar para vivir. Ese documento expone los retrocesos impuestos a las conquistas constitucionales de las mujeres y grupos LGBT+, lo cual ha acentuado la violencia de género y los discursos de odio promovidos por políticos y gobernantes (Wandelli, 2019).

El tecnofeminismo generado desde el grupo en Facebook Mujeres Unidas contra Bolsonaro visibilizó una agenda interseccional que encuentra puntos de convergencia en las críticas a un sistema políticoeconómico neoliberal en el que se sitúan las raíces del neoconservadurismo evangélico y el posfascismo presente en Brasil que vulnera, estigmatiza y discrimina.

Las diversidades y la eliminación de las desigualdades que encarnan las mujeres que formaron parte de este grupo no son posibles en un sistema de este tipo que, por sus expresiones ideológicas, como las antes mencionadas, obstaculiza el avance de la democracia, así como el fortalecimiento de Estados laicos en los que la igualdad en la diferencia y el derecho a decidir sobre el propio cuerpo, en sus diversas modalidades, estén garantizados.

\section{Fuentes}

Aguirre, Martin

2018 "Ni tan tan, ni muy muy", en El País Uruguay, 14 de octubre <https: / /www.elpais.com.uy/ opinion / columnistas / martin-aguirre / - 1 . html> [3 de agosto de 2019].

ARIAS, JuAN

2018 "O voto das mulheres desafia a extrema direita brasileira”, en El País Brasil, 14 de septiembre <https://brasil.elpais.com/brasil/ 2018/09/14/opinion/1536933199_059245. html> [3 de agosto de 2019].

BáRCENAS BARAJAS, Karina

Y NoHemí PREza CarReño

2019 "Desafíos de la etnografía digital en el trabajo de campo onlife", en Virtualis Revista de Cultura Digital, vol. 10, núm. 18, pp. 134-151.

Becker Fernanda

2018 "Grupo 'Mulheres contra Bolsonaro' no Facebook sofre ataque cibernético", en $E l$ País Brasil, 16 de septiembre <https: / /brasil. elpais.com/brasil/2018/09/14/politica/ 1536941007 569454.html> [3 de agosto de 2019].

Branco de Castro Ferreira, Carolina

2015 "Feminismos@web: linhas de ação e maneiras de atuação no debate feminista contemporáneo", en Cadernos Pagu, núm. 44, pp. 199-228 <https://periodicos.sbu.unicamp. br / ojs /index.php/cadpagu/article/view / $8637329 / 5043>$ [3 de agosto de 2019].

BRASIL DE FATO

2018 "Mulheres Unidas Contra Bolsonaro lançam manifesto sobre ato de sábado (29)", en Brasil de Fato, 27 de septiembre <https: / /www. brasildefato.com.br/2018/09/27/mulheresunidas-contra-bolsonaro-lancam-manifestosobre-ato-de-sabado-29/> [3 de agosto de 2019].

Castells, Manuel

2012 Redes de indignación y esperanza. Los movimientos sociales en la era de Internet, Alianza Editorial, Madrid, 296 pp.

Hill Collins, Patricia y Valerie Chepp

2013 "Intersectionality", en Georgina Waylen, Karen Celis, Johanna Kantola y Laurel Weldon (eds.), The Oxford Handbook of Gender and Politics, Oxford University Press, Oxford <https: / / sage-pilot.uq.edu.au / files / 151 / oxford_handbook_intersectionality.pdf> [18 de diciembre de 2019]. 
Hine, Christine

2015 Ethnography for the Internet: Embedded, Embodied and Everyday, Bloomsbury Publishing, Londres, $221 \mathrm{pp}$.

Jiménez, Carla, Heloísa Mendonça,

Regiane Oliveira, Marina Rossi

y Ricardo Della Coletta

2018 "Mulheres quebram o jejum das ruas no Brasil com manifestações contra Bolsonaro", en El País Brasil, 30 de septiembre <https: / /brasil. elpais.com/brasil / 2018/09/30/politica / 1538270819_523141.html> [3 de agosto de 2019].

Matos, Carolina

2017 "New Brazilian feminisms and online networks: Cyberfeminism, protest and the female 'Arab Spring”, en International Sociology, vol. 32, núm. 3, pp. 417-434.

Mujeres EvangélicAs

en Defensa de la Democracia

s/f "Mulheres evangélicas em defesa da democracia \#NaoEmNossoNome", en Petição Pública Brasil <https: / peticaopublica.com.br/ pview.aspx?pi=naoemnossonome $>$ [ 3 de agosto de 2019].

Navarro, Celina, Luisa Martínez-García

y Simón Vialás Fernández

2018 "Usos y valoración de Facebook como herramienta para la lucha contra la violencia de género en México", en Teknokultura. Revista de Cultura Digital y Movimientos Sociales, vol. 15, núm. 2, pp. 285-299.

Ramos, Marcella

2018 "\#ELENÃO supera \#ELESIM nas redes", en Revista Piauí, 1 de octubre <https://piaui. folha.uol.com.br/elenao-supera-elesimnas-redes / > [3 de agosto de 2019].

Romero Sánchez, Amparo

2014 "La utopía postfeminista: del ciberfeminismo al tecnofeminismo", en Cuadernos del Ateneo de La Laguna, núm. 32, pp. 156-169.

Rovira Sancho, Guiomar

2018 "El devenir feminista de la acción colectiva: las redes digitales y la política de prefiguración de las multitudes conectadas", en Teknokultura. Revista de Cultura Digital y Movimientos Sociales, vol. 15, núm. 2, pp. 223-240.
SÁnchez, Felipe

2018 "La movilización de las mujeres contra Bolsonaro en Brasil también se libra en Internet", en El País, 5 de octubre <https: / / elpais.com/ internacional / 2018/10/04/actualidad / 1538669047_046296.html> [3 de agosto de 2019].

Santos, Marcelo

2018 "Mulheres evangélicas formam a resistência a favor de Haddad e da democracia", en Rede Brasil Atual, 27 de octubre <https:// www.redebrasilatual.com.br/eleicoes $2018 / 2018 / 10 / \mathrm{mulher-evangelicas-}$ formam-a-resistencia-a-favor-de-haddade-da-democracia/> [3 de agosto de 2019].

Silva Reis, Josemira

2017 "Feminismo por hashtags: as potencialidades e riscos tecidos pela rede", en 11 Seminário Internacional Fazendo Gênero \& 13 Women's Worlds Congress (Anais Eletrônicos) <http:// www.en.wwc2017.eventos.dype.com.br/ resources / anais / 1503731675 ARQUIVO_ josemirareis_fazendogenerov2.pdf $>$ [3 de agosto de 2019].

TORET, JAVIER (COORD.)

2013 "Tecnopolítica: la potencia de las multitudes conectadas", en El sistema red 15M, un nuevo paradigma de la política distribuida (IN3 Working Paper Series), Universitat Oberta de Catalunyaf, Barcelona, pp. 17-54.

Traverso, Enzo

2018 Las nuevas caras de la derecha, Siglo xxI Editores, Buenos Aires, 160 pp.

VAN DIJCK, José

2016 La cultura de la conectividad. Una historia crítica de las redes sociales, Siglo xxI Editores, Buenos Aires, 304 pp.

WAJCMAN, JUDY

2006 El tecnofeminismo, Cátedra/Universitat de València/Instituto de la Mujer, Madrid, 200 pp.

WANDELLI, Raguel

2019 "Mulheres Unidas Contra Bolsonaro denunciam à onu violação de direitos humanos", en Jornalistas Livres, 10 de marzo <https: / / jornalistaslivres.org / mulheres-unidas contra-bolsonaro-denunciam-violacao-dedireitos-humanos-na-onu/> [3 de agosto de 2019]. 